\title{
ERRATA
}

Artigo originalmente publicado com erro na data de recebido

\section{Aspectos morfológicos de frutos, sementes, germinação e plântulas de Hymenolobium petraeum}

Morphological aspects of fruits, seeds, germination and seedlings of Hymenolobium petraeum

\author{
Luciene Zagalo de Oliveira' ${ }^{\mathrm{I}}$ Fabiano Cesarino ${ }^{\text {II }}$ Tammya de Figueiredo Pantoja ${ }^{\text {III }}$ \\ Fabíola Vitti Môron
}

Para html ou PDF, acesse, respectivamente:

http:/www.scielo.br/scielo.php?script=sci_arttext\&pid=S0103-84782010000800010\&lng=en\&nrm=iso\&tlng=pt ou http://www.scielo.br/pdf/cr/v40n8/a697cr1876.pdf

We sugest that subscribers photocpy this correction and insert the copy at the appropriate place where the article originally appeared.

Sugerimos que uma fotocópia das correções seja inserida na página correta onde o artigo apareceu originalmente.

IFaculdade de Ciências Agrárias e Veterinárias (FCAV), Universidade Estadual Paulista (UNESP), 14884-900, Jaboticabal, SP, Brasil. E-mail: luciene_zagalo@yahoo.com.br. Autor para correspondência.

"Instituto de Pesquisas e Científicas e Tecnológicas do Estado do Amapá (IEPA), Macapá, AP, Brasil.

IIIPrograma de Pós-graduação em Biodiversidade Tropical, Universidade Federal do Amapá (UNIFAP), Macapá, AP, Brasil.

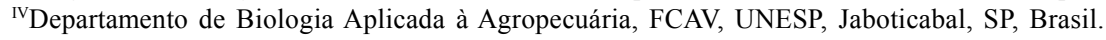

